\title{
BuSINESS DEVELOPMENT IN EMERGING MARKETS: THE IMPACT ON THE SPENDING BEHAVIOUR OF ELDERLY CAREGIVERS OF FAMILY MEMBERS WiTh HIV/AIDS IN SOUTH AFRICA
}

\author{
Bruce R Klemz \\ Department of Marketing, St Cloud State University \\ Christo Boshoff \\ Department of Business Management, University of Stellenbosch \\ Noxolo-Eileen Mazibuko \\ Department of Business Management, Nelson Mandela Metropolitan University
}

Accepted June 2010

\begin{abstract}
Business development in emerging markets, known as the 'base of the pyramid', is not without financial risk, and a key concern in South African communities are the costs associated with HIV/AIDS. Due to the enormous demand for healthcare, many governments have opted for home-based care systems. Caregivers are mainly older women and their financial survival is critically important. We found that as the patient's illness progressed: 1) the cultural norm ubuntu led the caregiver to increase spending on the patient and a decreased spending on themselves and 2) the social pressure of stigma led to a very dramatic drop in direct interpersonal assistance to the patient and an increase in spending on themselves. Their resulting coping strategies and implications for economic development are discussed.
\end{abstract}

Key words: emerging markets, cultural, health services

JEL I11, 32, J 14, 17

1

\section{Introduction}

In leading marketing journals (Steenkamp, 2005; Bolton, 2003), the popular business press (e.g. Demos, 2006; Racanelli, 2006) and in international monetary policy (e.g. Blejer, 2006; Pasiouras, Gaganis \& Zopounidis, 2006), there is a growing interest in emerging market consumers. Believers in the 'base of the pyramid' (hereafter BOTP) concept (e.g. Burgess \& Nyajeka, 2006; Prahalad \& Hart, 2002) acknowledge that while the personal income levels of these emerging market consumers are very low, these markets consist of nearly four billion people and that the business opportunities these markets offer cannot be ignored (Prahalad, 2005). While this large population is not homogenous, research into BOTP suggests that future growth in business markets will come from serving these massive but currently underserved markets. The basic tenant is that this growth opportunity will emanate from the huge bottom tiers in these markets, the so-called 'base of the pyramid'. However, business development in emerging markets is not without considerable financial risk, and a key concern for such business development in parts of the developing world is the HIV/AIDS pandemic (e.g. Chao, Pauly Szrek, Pereira, Bundred, Cross \& Gow, 2007; Addison, Mavrotas \& McGillivray, 2005; Lockwood, 2005).

The direct economic costs (e.g. medicine, hospitalisation) of HIV/AIDS and the impact on business development have received a lot of attention in emerging markets (e.g. Chao et al., 2007; McDonald \& Roberts, 2006; Bell, Devarajan \& Gersbach, 2006; Garrett, 2005; van Wyk, Dahmer \& Custy, 2004). However, 
without a broader understanding of the indirect economic costs (e.g. reduced labour, reduced spending for non-medical goods, cost of care and cost to the caregiver) associated with HIV/AIDS, leveraging the large untapped consumer group at the 'base of the pyramid' would be impossible (Burgess \& Nyajeka, 2006). Of specific concern is the economic impact on the elderly family member who provides the bulk of the health care to those infected family members. More specifically, how do these elderly caregivers financially and practically cope with the burden of caregiving?

In this study, we assess the economic impact on, and their financial coping strategies used by, the elderly caregivers as they care for an HIV/AIDS afflicted family member. More specifically, we focus on the elderly caregivers in the emerging market of South Africa. While a study in Thailand assessed the social and economic support provided by the elderly caregivers (Knobel, 2001), a thorough review of the literature revealed no study has addressed the impact of direct and indirect costs on the elderly caregivers of HIV/AIDS patients.

Assessing the economic impact of HIV/AIDS on the elderly caregiver is, however, more complex than simply measuring the money and time spent as both cultural norms and social pressures can play a significant role. In South Africa, the tribal and cultural norms of blacks are meticulously honoured by the elderly tribal members (Freeman \& Nkomo, 2006:504; Moore \& Henry, 2005:148). For South African Xhosa and Zulu collectivist cultures, buntu $^{l}$ stresses harmonious inter-personal relationships, caring for each other, sharing and self-sacrifice. Therefore, Xhosa and Zulu elders commonly provide both social and economic support for their family well beyond what is considered common in the developed world (Freeman \& Nkomo, 2006:504). The high infection rate of HIV/AIDS has generated a strong stigma toward this disease which has the undesirable outcome of reduced access to treatment and the level of care provided.

We found that as the patient's illness progressed, the cultural norm of ubuntu influenced the caregiver's spending assistance to increase, but the social pressure of stigma led to a very dramatic drop in non-monetary and direct interpersonal assistance. The impact of these norms on their own non-medical spending was mixed. Not surprisingly, we found that as the caregiver spent more money on the patient, their own non-medical spending decreased. However, we found that as their non-monetary assistance decreased, their own non-medical spending increased.

The structure of this paper is as follows. We position our study within the extant consumer research literature. This is followed by a discussion of the theoretical model used to guide the study and the specific hypotheses tested in this research. A detailed discussion of our methodology precedes our results and hypotheses tests. The paper concludes with a discussion of the results and implications.

\section{2}

\section{Literature overview}

While the developing world market consists of up to 4 billion people and a multi-trillion dollar-market potential, many businesses may feel that the extreme wealth inequity in these countries means that the poor cannot adequately participate in a global market economy. However, the sales potential in the developing world is huge (Prahalad \& Hart, 2002) and research suggests that economic and social transformations taking place in the developing world may lead to considerable sales potential at the 'bottom of the pyramid' for multinational corporations (Prahalad \& Hammond, 2002).

In the developed world, advances in medical technology have resulted in falling patient mortality rates and social science research has shifted to issues such as quality of life instead (Sikkema, Hansen, Meade, Kochman \& Lee, 2005; Mannheimer, Matts, Telzak, Chesney, Child \& Friedland, 2005). The exact opposite is true in the developing world where the key problems regarding HIV/AIDS have not changed: high medical expense, reluctant behavioural modifications, expanding infection rates and increased mortality. In the developing world, the research focus has been on demographic changes, infection rates (almost 5.7 million South Africans are estimated to be infected or 18.1 per cent of the 
15-49 age group), mortality rates (in South Africa the average life expectancy has dropped to 38 years), the impact on business profitability and changing consumption patterns (UNICEF 2007; van Aardt, 2004, 2002).

Research into this extended impact scenario acknowledges that the impact of HIV/AIDS is not merely on the patient, but falls on the entire extended family, with the bulk of the impact being on the elderly family members (Moore \& Henry, 2005:157). Van Aardt (2002, 2004) and Moore and Henry (2005) found that such families are likely to cut back first on durable goods such as televisions and cars, and to a lesser extent on semi-durable goods such as footwear, clothing and textiles. At the same time, families will take children out of school to care for the ill, or because they can no longer afford school fees, uniforms and books. Ultimately families adapt by eating less and curtailing their spending on essentials such as food. By 2012, van Aardt estimates, that (at current prices) about R7 bn less will be spent on grain products than if there was no HIV/AIDS, and about R4,6 bn less on bakery products. Spending on meat products is projected to be R14 bn less than in a nonHIV/AIDS scenario, and spending on fruit and vegetables will shrink by $\mathrm{R} 7,8$ bn. Economic models predict that the fast-moving consumer goods sector is most vulnerable, because up to 35 per cent of the SA households that constitute that market are currently HIVpositive (Kahn, 2003).

In addition, in South Africa, the massive infection rates and high mortality rates are putting untold pressure on the very social fabric of society (Kahn, 2006) and the family structure itself (Moore \& Henry, 2005). Recently, research has noted that HIV/AIDS is not only a social concern, but it is being seen as an impediment to economic progress, aggravating the problems associated with poverty (O'Grady, 2004). Slowing population growth and lower life expectancies will lead to high unemployment, a shortage of skilled labour and reduced foreign investment. Under these circumstances the domestic market will shrink to basic goods and services.

Again, these estimates do not refer to the impact of the pandemic on the health-care system of the country. In South Africa, the stress on the medical care system is extreme and scarce financial resources are not allowing the community to find the success seen in the developed world. However, the lack of resources does not only affect the level of caring, but also impacts on the availability of medicine and access to knowledgeable medical professionals. The sheer weight of demand for medical care has forced exasperated elderly family caregivers to accept a 'home care' (Beresford, 2004) or 'home-school-community partnerships' (van Wyk \& Lemmer, 2007) solution for those infected with HIV/AIDS. In other words, patients, or more commonly the elderly caregiver, will only collect their medicine at clinics and then administer their own treatment at home (Beresford, 2004) with little or no expert assistance.

The situation is worsened when one considers that affected households start using their meager savings to finance health care. For instance, when care is needed in an affected household by an elderly family member, they reduce their savings by 56.7 per cent and borrow significantly more money than unaffected households do (van Aardt, 2004). An adverse impact on the elderly was also noted by Knobel et al. (2001) in Thailand. They found that the impact on the elderly caregiver was both social and economic.

\subsection{When cultural norms and stigma collide}

How a culture responds to such stresses is an active area of social science research (e.g. Patrick et al., 2004), but much of these research focus on the patient level. However, the impact of HIV/AIDS on the family unit can be horrendous, changing even the most basic family functions (Moore \& Henry, 2005; van Aardt, 2004; Weiser et al., 2003).

Historically, black South African cultures ${ }^{2}$ (in this study primarily Xhosa and Zulu) are, at the tribal level, collectivist in nature and a key cultural attribute is ubuntu (pronounced $u h$ boon-too). Ubuntu loosely means 'I am because you are', and the concept places a high value on harmonious inter-personal relationships, feeling secure, a sense of belonging and working for the common good (Khumalo, 2001; Mbigi \& Maree, 1995). 
Many empirical studies that have attempted to identify the antecedents of a successful relationship concur that trust, commitment, shared values and communication (e.g. Morgan \& Hunt, 1994; Ganesan, 1994; Andaleeb \& Anwar, 1996; Macintosh \& Lockshin, 1997) are key requirements to a successful relationship.

Above all, ubuntu stresses harmonious inter-personal relationships, caring for each other, sharing and self-sacrifice. It stresses the avoidance of conflict and confrontation and is more concerned about the whole rather than individual gain (Khumalo, 2001). Based on this prevailing cultural collectivist norm, we have formulated the following hypotheses $(\mathrm{H} 1$, $\mathrm{H} 2$ and $\mathrm{H} 3$ ):

H1: As the patient illness progresses the caregiver's spending will increase

H2: As the caregiver's spending assistance increases, their financial coping strategies will increase

H3: As the caregiver's financial coping strategies increase, their non-medical spending will decrease

However, current social research suggests that HIV/AIDS poses an unseen threat to cultural norms. Early HIV/AIDS research (Chesney \& Smith, 1999; Laryea \& Gien, 1993; Ingram, 1999; Grove, Kelly \& Liu, 1997; Taylor, 2001) suggests that generalised stigma toward this disease resulted in both delays in testing and subsequent disclosure. They note that this delay may have helped speed up its spread in certain communities under threat because it provides a cultural barrier to prevention (De Cook, Mbori-Ngacha \& Marum, 2002). While it appears that in developed nations education and improved treatment options have reduced the stigma associated with HIV/AIDS, this is not seem to be true in the developing world (De Cook, Mbori-Ngacha \& Marum 2002).

In the developing world, the problem is compounded. Previous research has shown that moral norms within a society can increase the level of stigma for both the patient and the family (Kalichman \& Simbayi, 2003). For example, a study of HIV/AIDS patients in Botswana, Letamo (2003) found that this stigma could lead to significant discrimination. Letamo (2003) noted that attempts have been made to reduce stigma via education and shifting to home-based care, but treating HIV/AIDS differently from other diseases may have actually had the opposite result (De Cook, Mbori-Ngacha \& Marum, 2002).

In Thailand, Kittikorn, Street and Blackford (2006) and Moore and Henry (2005) in Togo found that a conservative moral climate actually increases the level of stigma associated with HIV/AIDS. They note that a 'public judgment' was created in this moral climate and the level of stigma grew for both the patient and the caregiver. They found that stigma led the caregiver to conceal their support activities and in some cases, to withdraw from all support activities in order to reduce the stigma on themselves. This public judgment was internalised and can lead to a dramatic increase in stigma (Lekas, Siegel \& Schrimshaw, 2006). The desire to avoid stigma can become overwhelming. Based on this research, the following hypotheses (H4, H5 and H6) were formulated:

H4: As the patient illness progresses the caregiver's time helping will decrease

H5: As the caregiver's time spent providing assistance increases, their non-financial coping strategies will decrease

H6: As the caregiver's non-financial coping strategies increase, their non-medical spending will increase

\subsection{Model description}

The conceptual framework used in this study was adapted from the review of Booysen and Arntz (2003) and is detailed in Figure 1. 
Figure 1

Elderly coping strategy model presented in this study

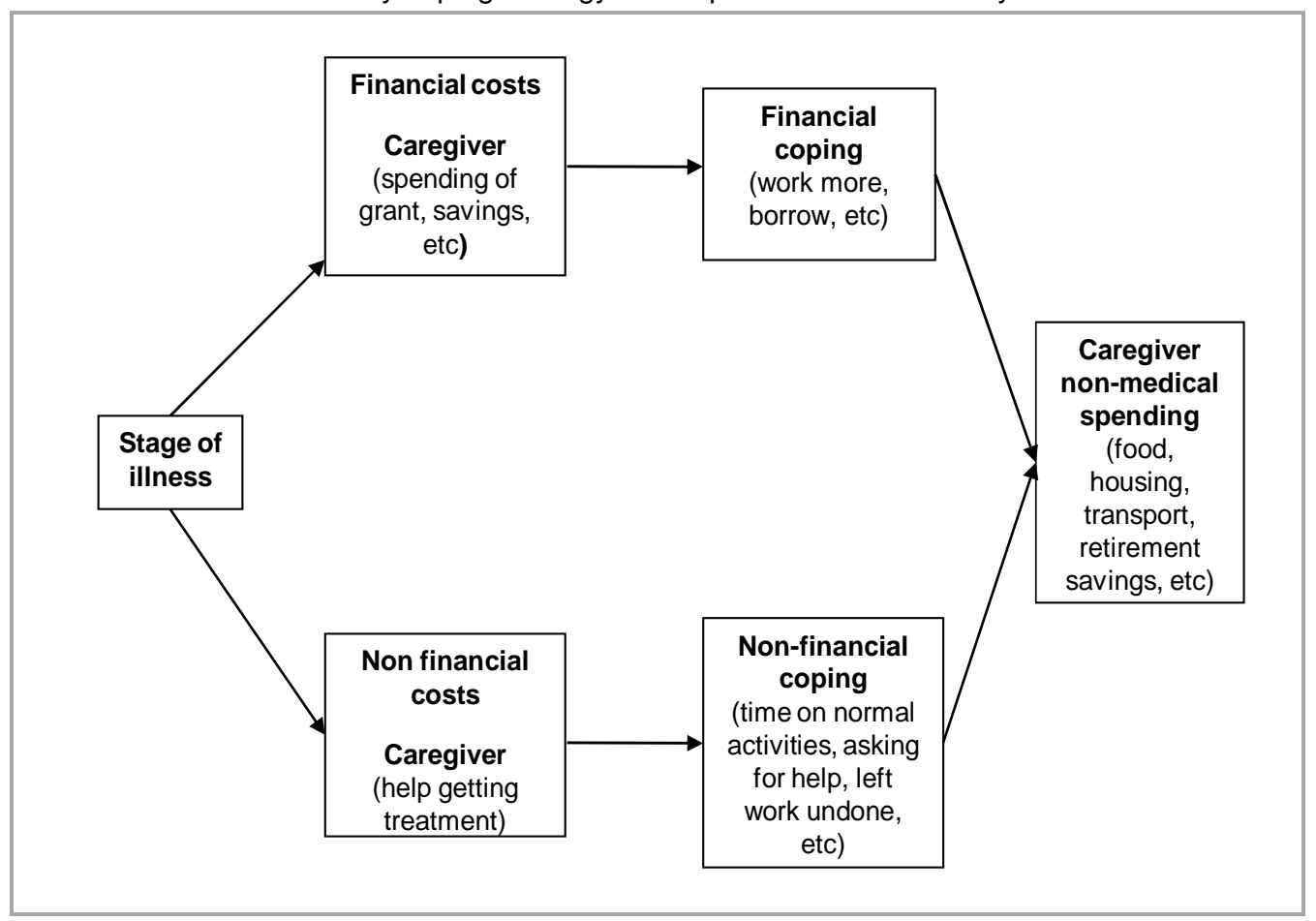

\subsection{Measurement}

Stage of Illness: This 5-point interval scale measure was scaled by the in-home nurse based on the patient's CD4 + T-lymphocyte/ $\mu \mathrm{L}$ count (e.g. Linn, Monnig, Cain \& Usoh, 1993; Sebesta \& LaPlante, 1996).

Financial costs and non-financial costs: the caregiver's spending of their income (grant income), and time with patient (care, transport, etc.) were adapted from Bachmann and Booysen (2003) and Russell (2003).

Financial coping and Non-financial coping: working more, borrowing more, asking for help, letting work go undone were adapted from Booysen, Geldenhuys and Marinkov (2003) and Russell (2003).

Non-medical spending: reductions in spending (food, housing, transport, etc.) and personal savings were adapted from Booysen, Geldenhuys and Marinkov (2003).

\section{3}

\section{Methodology}

\subsection{Sample and community profile}

The location of this study was a township outside a large South African metropolitan area. The approximate township population at the time of this study was $\mathrm{N}=2,500,000$. The ethnic make-up of this township was predominantly Xhosa, which is one of the two largest indigenous tribal cultures in South Africa (the other being Zulu).

Questionnaires were personally administered by trained staff that consisted of nurses who worked for several NGO in-home health care providers. Because patients with AIDS/HIV still bear a strong social stigma nurses were used to access these subjects and their caregivers because of the nature of the nature of the data being collected and their close relationship with all the family members in an afflicted household. The nurses were trained by the authors and they were monitored throughout the study. Families were selected 
for the study based on a convenience sampling basis from those available within the NGO data base.

Questionnaires were offered to the participants in English, Afrikaans, or Xhosa. Due to the intimate relationship between our fieldworkers (nurses) and patient's family, the response rate for this study was 100 per cent. Note that the data collection was executed during the nurses' regular home visits and as a result there were no refusals. The final sample size was 50.

Our respondents, the elderly caregiver, were 98 per cent female and 2 per cent male and ranged in age from 50 to 93 with a mean of $61.2(\sigma=9.82)$. Two per cent of these caregivers were spouses of the afflicted, 70 per cent were parents of the afflicted, 6 per cent were extended family, and 2 per cent were family friends. In terms of formal education, 2 per cent of the caregivers had no formal education, 14 per cent had primary education, 68 per cent had a high school education, and 16 per cent had some form of tertiary education. Regarding their income source, 4 per cent of these elderly caregivers worked full-time, 4 per cent worked part-time, 76 per cent received government grants/welfare, 6 per cent obtained money from other family members, and 10 per cent received money from other sources. Their mean monthly income was R638.1 $(\sigma=\mathrm{R} 152.1)$ or $\$ 91.15$ $(\sigma=\$ 21.72)$ in US dollars at the time of the survey.

\subsection{Analysis}

Currently, there are two common methods for analysing complex multiple dependence relationships. The first, Maximum Likelihood estimation, such as that used in LISREL (Jöreskog \& Sörbom, 1984), is an analysis method based on a factor construct concept that places stringent demands on the data. The second, PLS (Wold, 1974), the analysis methodology used in this study, is based on a component construct concept that places the same demands on the data as OLS regression does. Previous research suggests (Fornell \& Bookstein, 1982) that analysis techniques such as LISREL are better suited for theory testing of complex relationships, while PLS is better suited for explaining complex relationships. The main purpose of PLS, therefore, is the prediction of empirical and/or theoretical variables (Fornell \& Bookstein, 1982), the primary objective of this study.

As in regression analysis, PLS requires that each variable be measured using interval scale measures. Consistent with previous attitude research, each latent variable indicator in this study was measured using Semantic Differential questions, ranging from five ('often') to one ('never') and these endpoints have been used in both cultural setting and to assess their impact on response bias (Smith \& Reynolds, 2001). To aid in interpretation, all the parameter estimates in this study are expressed in a standardised form to compare their relative strengths. In PLS, parameter significance is assessed using a 'jack-knife' technique to construct a distribution of parameter estimates (Dijkstra, 1983). Using these estimates, the mean and standard deviation of the parameter estimates are used to assess statistical significance. In addition, model goodness-of-fit $\mathrm{R}^{2}$ estimates are provided following Hulland (1999:202).

\section{4 \\ Results}

The empirical results are depicted in Figure 2. To examine the theoretical construct measures, we examine the loadings of each indicator on their respective latent variable. In PLS, the numerical parameter estimate is the simple correlation coefficient between the indicator and the latent variable. These results suggest that the theoretical constructs reflect the meaning of their underlying variables. The overall model $\mathrm{R}^{2}$ is 0.72 , illustrating good overall model fit for a PLS model. 
Figure 2

The resulting elderly coping strategies found in this study.

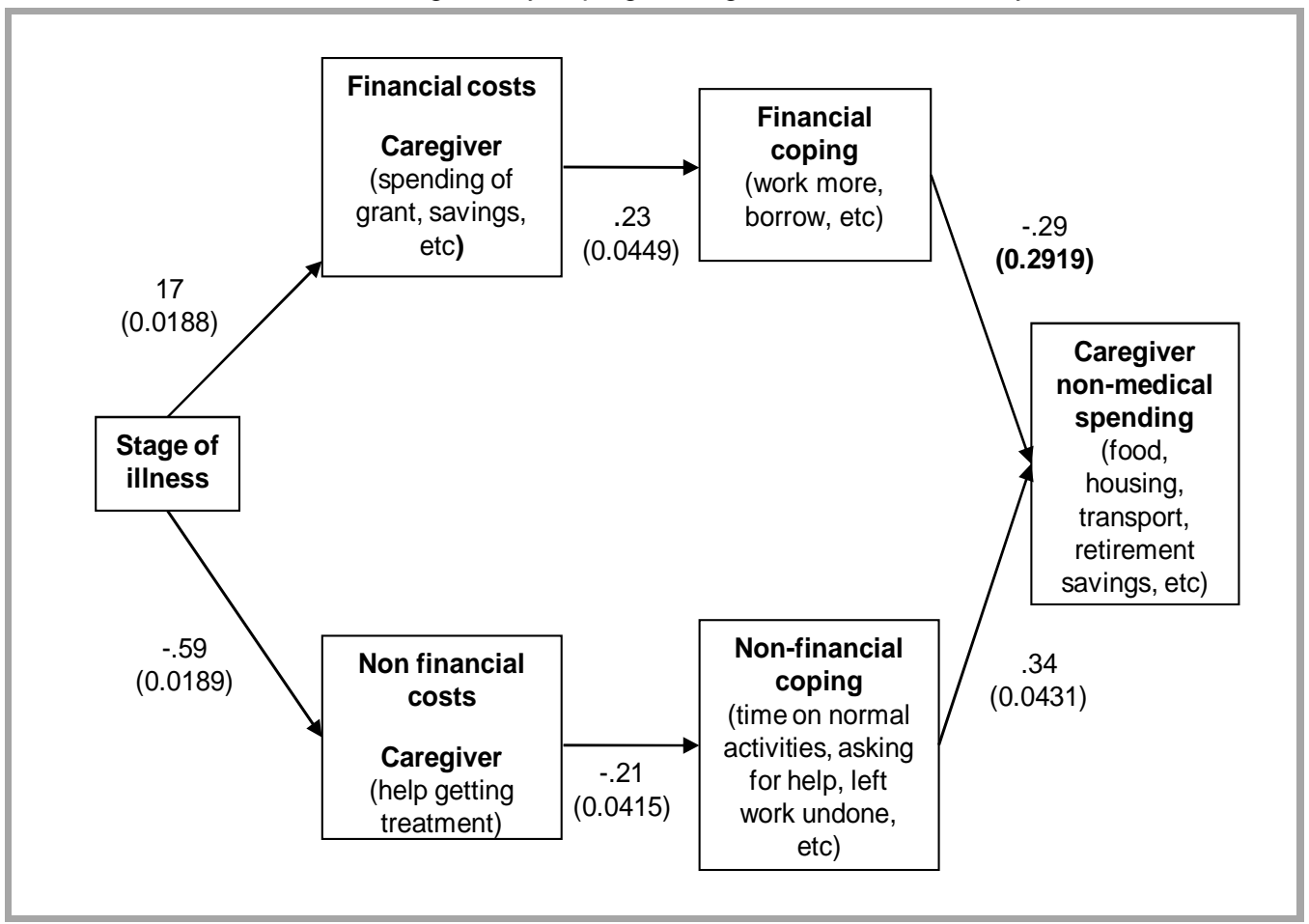

We find that as the patient's illness progresses, the caregiver spends more money aiding the patient (0.17) in support of H1. Our results also suggest that the more money the caregiver provides for the patient's health care, the impact on the caregiver's financial activities is increased (0.23). They work, borrow, etc. more to compensate for their spending on patient activities, supporting $\mathrm{H} 2$. Not surprisingly, this behaviour has a negative effect on their normal non-medical spending (-0.29) in strong support of $\mathrm{H} 3$.

We also find that as the patient's illness progresses, the caregiver spends less time directly helping (-0.59), finding which provide strong support for $\mathrm{H} 4$. As the time and effort the caregiver provides for the patient's health care increases, the impact on the caregiver's time spent on normal activities is strongly reduced. In other words, they cannot spend time doing normal activities because of the care they provide $(-0.21)$, which is in support of H5. Additionally, the more the caregiver uses non-financial coping strategies (asking for help, letting work go undone, etc.) they seem to spend more money on their own nonmedical needs (0.34), which strongly supports H6.

\section{5}

\section{Discussion}

We find that the coping strategies used by the elderly caregivers are complex. Cultural norms drive the elderly family member to provide assistance and spend money for the sick family member but the fear of social rejection can, at the same time, cause them to physically distance themselves from the ill family member they want to help. Both of these activities have mixed impacts on the caregiver's non-medical spending, which can worsen an already stressed South African economic environment.

Our research in this township, like the social research of many others, has found that in South Africa the sick are hiding their disease from friends and family for fear of rejection. In 
essence, the social norm of ubuntu is being trumped by the stigma of HIV/AIDS. We found that as the illness progresses, the caregiver reduces their level of non-monetary help and is directly impacted economically from the illness of their family member.

While outside the scope of our study, we found in this township this stigma is so strong that it often leads to eventual abandonment by the elderly family caregiver. For the patient, this stigma can also combine with a fear of the mixed motives of their elderly caregiver. In essence, many of the sick fear the loss of tangible goods (money, property, etc.) due to their death and this fearfulness further leads to distrust and reluctance (failing) to disclose their illness to their caregiver (van Dyk, 2005:324). Lastly, we found that the stigma is so high that many of the sick do not apply for grants (welfare) payments for fear of an HIV/AIDS diagnosis, further worsening the economic impact on both themselves and their elderly caregiver. This is an interesting and important area for future economic and business research. Little wonder that the spread of HIV/AIDS is so swift in this type of social and cultural environment.

In this township HIV/AIDS stigmatises both infected people and uninfected people working in the field (Uys \& Cameron, 2004). This "secondary stigma" can have a powerful effect on the caregiver's status with family, friends and the public at large. Being avoided because he or she works with people with HIV/AIDS can be very stressful for a caregiver. Ostracism of this kind can deprive the caregiver of muchneeded support (van Dyk, 2005). Additionally, caregivers are often not adequately trained to care for patients with HIV/AIDS, and those who are trained carry a very heavy patient load. Because South African society cannot afford to lose its caregivers to stress and burnout, recent research finds that support for caregivers is critical (van Dyk, 2005).

These scenarios have not gone unnoticed (e.g. Cohen, 2000; Weiser et al., 2003). For example, many NGOs (non-governmental organisations), Oxfam (through their educational outreach efforts) and others are now actively involved in outreach efforts not merely to prevent the spread of HIV/AIDS, but to reduce the stigma associated with this disease (van Dyk, 2005:324). Their work with churches and in other social settings is an attempt to reframe HIV/AIDS as a manageable disease, not a death sentence. To reduce the financial impact on the elderly caregiver, many of these aid organisations are also involved with skills-development activities and particularly life-skill education for children (Department of Health, 2005:4). The goal here is to train the elderly caregiver in both targeted medical training and an income-generating skill that can be performed at home (Uys \& Cameron, 2004).

However, these aid organisations face an uphill battle. Cherian (2004) reveals that educators and aid organisations are faced with problems in educating learners about HIV/AIDS. According to Cherian (2004), some teachers, based on their cultural background, find it difficult and uncomfortable to discuss issues concerning sexual matters with learners. Additionally, both parents and educators consider open talk about sex as a cultural taboo (Zungu, 2002).

While these results are troubling, social pressures continue to strive for improved care for the ill and support for their caregiver (Uys \& Cameron, 2004). Recently in South Africa, many pensioners who were health professionals (doctors and nurses) have started their own support groups to assist AIDS sufferers and the affected caregivers by volunteering their services in areas such as bathing sufferers, issuing food parcels, counseling and taking over their families with regards to helping these families manage their homes and with the resulting orphaned children (Ogden, Esim \& Grown, 2004:13; Akintola 2004:3-4). In the KwaZulu-Natal province, individuals in the community are even burying neighbours who cannot afford to do anything for themselves. These positive trends can also be found in the township under study in our research (Mturi, Xaba \& Sekokotla, 2005).

\section{6}

\section{Conclusion}

The HIV/AIDS pandemic is dramatically impacting the current economy of South Africa and the long-term implications of this disease 
and its rapid spread is unprecedented in modern history. Literally complete generations of wage earners are being infected with this virus and its economic and social impact are clearly huge.

The core of the 'base of the pyramid' concept (Prahalad, 2005) suggests that while personal income levels are very low in the developing world, the sheer size of these markets means that this business opportunity cannot be ignored. However, business development in emerging markets is not without risk, largely due to the impact of HIV/AIDS (e.g. Chao et al., 2007). In our study, we assess a key unaddressed issue in South Africa: the direct economic and indirect social costs for elderly caregivers of family members with HIV/AIDS.

We found that in this township while the cultural norm of ubuntu leads family members to care for ill or needy family members, the stigma associated with HIV/AIDS severely reduces the physical help provided to sick family members. Clearly, this mixed result suggests further research be done in this area.
The end result of this mixed outcome for the patient is tragic, but the economic impact for South Africa is equally troublesome. Our results suggest that in this township, as the elderly caregiver provides financial assistance to the ill family member, they attempt to cope with this spending by working or borrowing more and this has a very negative impact on their own non-medical spending. We also find that as the illness progresses, the elderly caregiver reduces their non-financial assistance. In short, they avoid physical contact with the patient and they attempt to cope by asking for help and letting work go undone. The effect on their non-medical spending is mixed. This complex relationship between financial and non-financial help provided by the elderly caregiver can have a double impact on the developing economy: the direct cost of HIV/AIDS is enhanced by the reduction of spending by those who care for them. Therefore, in this township the promises offered by the 'base of the pyramid' theory in South African township communities may never be achieved.

\section{Endnotes}

1 Ubuntu was noted by Steenklamp (2005) as a success factor in emerging consumer markets

2 South Africa officially recognises eleven different languages. Black tribal affiliations include Ndebele, Sotho, Swazi, Tsonga, Tswana, Venda, Xhosa, and Zulu. However, Xhosa and Zulu are the two major black ethnic groups in the South African townships and are the subjects of this research

\section{References}

ADDISON, T., MAVROTAS, G. \& MCGILLIVRAY, M. 2005. Development assistance and development finance: evidence and global policy agendas. Journal of International Development, 17(6):819-837.

AKINTOLA, O. 2004. The gendered burden of home-based care giving. Policy brief: Health economics and HIV/AIDS Research Division. University of KwaZulu Natal, August 2004.

ANDALEEB, S.S. \& ANWAR, S.F. 1996. Factors influencing customer trust in salespersons in a developing country. Journal of International Marketing, 4(4):35-52.

BACHMANN, M.O. \& BOOYSEN, F.L.R. 2003. Health and economic impact of HIV/AIDS on South African households: a cohort study. BMC Public Health, 3(14):1-8.

BELL, C., DEVARAJAN, S. \& GERSBACH, H. (2006). The long-run economic costs of aids: a model with an application to South Africa. The World Bank Economic Review, 20(1):55-89.

BERESFORD, B. 2004. Reflections and lessons from frontline treatment providers. In From Disaster to Development: HIV and AIDS in Southern Africa. Heywood, M. (ed.) Development Update, 5(3):265-291.

BLEJER, M.I. 2006. Economic growth and the stability and efficiency of the financial sector. Journal of Banking \& Finance, 30(12):3429-3432.

BOLTON, R. 2003. From the editor. Journal of Marketing, 67(Jan):1-3.

BOOYSEN, F.R. \& ARNTZ, T. 2003. The methodology of HIV/AIDS impact studies: a review of current practices. Social Science \& Medicine, 56(12):2391-2405. 
BOOYSEN, F. LE R., GELDENHUYS, J.P. MARINKOV, M. 2003. The impact on the South African economy: a review of current evidence. Working paper presented at the TIPS/DPRU conference on the challenge of growth and poverty: the South African economy since democracy, Johannesburg, South Africa. BURGESS, M. \& NYAJEKA, P. 2006. Market orientation and performance at the "base of the pyramid: the case of Zimbabwean retailers. Working paper, Marketing Science Institute.

CHAO, L.W., PAULY, M., SZREK, H., PEREIRA, N.S., BUNDRED, F., CROSS, C. \& GOW, J. 2007. Poor health kills small business: illness and microenterprises in South Africa," Health Affairs, 26(2): 474-482.

CHERIAN, L. 2004. Influence of culture and religion in HIV/AIDS Education in South Africa. International Conference on AIDS, University of the North, Pietersburg, South Africa, Jul 11-16:15.

CHESNEY, M.A. \& SMITH, A.W. 1999. Critical delays in HIV testing and care: the potential role of stigma. American Behavioral Scientist, 42(7):1162-1174.

COHEN, M.S. 2000. Preventing sexual transmission of HIV - new ideas from Sub-Saharan Africa. The New England Journal of Medicine, 342(13):970-972.

DE COOK, K., MBORI-NGACHA, D. \& MARUM, E. 2002. Shadow on the continent: public health and HIV/AIDS in Africa in the 21st century. The Lancet, 360(9326):67-72.

DEMOS, T. 2006. Exchange Wars. Fortune, 154(11):62-68.

DEPARTMENT OF HEALTH: REPUBLIC OF SOUTH AFRICA. 2005. Progress report on declaration of commitment on HIV and AIDS. Department of Health, Republic of South Africa.

DIJKSTRA, T. 1983. Some comments on maximum likelihood and partial least square methods. Journal of Econometrics, 22:67-90.

FORNELL, C. \& BOOKSTEIN, F. 1982. A comparative analysis of two structural equation models: LISREL and PLS applied to market data. Fornell, C. (ed.) A second generation of multivariate analysis, Praeger, New York.

FREEMAN, M. \& NKOMO, N. 2006. Assistance needed for the integration of orphaned and vulnerable children - views of South African family and community members. Journal of Social Aspects of HIV/AIDS, 3(3):503-509.

GANESAN, S. 1994. Determinants of long-term orientation in buyer-seller relationships. Journal of Marketing, 58:1-19.

GARRETT, L. 2005. The lessons of HIV/AIDS. Foreign Affairs, 84(4):51-65.

GROVE, K.A., KELLY, D.P. \& LIU, J. 1997. But nice girls don't get it. Journal of Contemporary Ethnography, 26(3):317-337.

HULLAND, J. 1999. Use of partial least squares (PLS) in strategic management research: a review of four recent studies. Strategic Management Journal, 20:195-204.

INGRAM, D. 1999. HIV-positive mothers and stigma. Health Care for Women International, 20(1):93-103. JÖRESKOG, K.G. \& SÖRBOM, D. 1984. LISREL VI: Analysis of linear structural relationships by maximum likelihood and least square methods, Mooresville, IN: Scientific Software.

KAHN, T. 2003. Incomes suffer as AIDS cuts deep into families. Business Day (Electronic ed.) 16 October. KAHN, T. 2006. Metropolitan's AIDS scenarios for 2025 include a winter of discontent. Business Day (Electronic ed.) 21 June.

KALICHMAN, S.C. \& SIMBAYI, L.C. 2003. HIV testing attitudes, AIDS stigma, and voluntary HIV counseling and testing in a black township in Cape Town, South Africa. Sexually Transmitted Infections, 79:442-447.

KHUMALO, R. 2001. Concern for others: A management attribute of excellent companies. South African Journal of Business Management, 32(1):57-65.

KITTIKORN, N., STREET, A.F. \& BLACKFORD, J. 2006. Managing shame and stigma: case studies of female carers of people with AIDS in Southern Thailand. Qualitative Health Research, 16(9):1286-1301. KLEMZ, B.R., BOSHOFF, C. \& MAZIBUKO, N.E. 2006. Emerging markets in Black South African townships: small local independently owned versus large national retailers. European Journal of Marketing, 40(5/6):590-610.

KNOBEL, J., VAN LANDINGHAM, M., SAENGTLENCHAL, C., \& IM-EM, W. 2001. Older people and AIDS: quantitative evidence of the impact in Thailand. Social Science \& Medicine, 52(9):1313-1327. 
LARYEA, M. \& GIEN, L. 1993. The impact of HIV-positive diagnosis on the individual, Part 1 - stigma, rejection, and loneliness. Clinical Nursing Research, 2(3):245-263.

LEKAS, H.M., SIEGAL, K. \& SCHRIMSHAW, E.W. 2006. Continuities and discontinuities in the experiences of felt and enacted stigma among women with HIV/AIDS. Qualitative Health Research, 16(9): 1165-1190.

LETAMO, G. 2003. Prevalence of and factors associated with, HIV/AIDS-related stigma and discriminatory attitudes in Botswana. Journal of Health, Population and Nutrition, 21:347-356.

LINN, J.G., MONNIG, R.L., CAIN, V.A. \& USOH, D. 1993. Stage of illness, level of HIV symptoms, sense of coherence and psychological functioning in clients of community-based AIDS counseling centers. Journal of the Association of Nurses in AIDS Care, 4(2):24-32.

LOCKWOOD, M. 2005. Will a Marshall plan for Africa make poverty history? Journal of International Development, 17(6):775-790.

MACINTOSH, G. \& LOCKSHIN, L.S. 1997. Retail relationships and store loyalty: a multi-level perspective. International Journal of Research in Marketing, 14:487-497.

MANNHEIMER, S.B., MATTS, J., TELZAK, E., CHESNEY, M., CHILD, C., WU, A.W. \& FRIEDLAND, G. 2005. Quality of life in HIV-infected individuals receiving antiretroviral therapy is related to adherence, AIDS Care, 17(1):10-22.

MBIGI, L. \& MAREE, J. 1995. Ubuntu - The spirit of African transformation management, Knowledge Resources, Randburg, South Africa.

MCDONALD, S. \& ROBERTS, J. 2006. AIDS and economic growth: a human capital approach. Journal of Development Economics, 80(1):228-250.

MOORE, A.R. \& HENRY, D. 2005. Experiences of older informal caregivers to people with HIV/AIDS in Lome, Togo. Ageing International, 30(2):147-166.

MORGAN R.M. \& HUNT, S.D. 1994. The commitment-trust theory of relationship marketing. Journal of Marketing, 58:20-38.

MTURI, A.J., XABA, T. \& SEKOKOTLA, D. 2005. Assessment of circumstances facing contemporary families in South Africa. School Research Report Number 66, University of KwaZulu Natal, Durban, February 2005.

O'GRADY, M. 2004. The impoverishing pandemic. In: From disaster to development: HIV and AIDS in Southern Africa. Heywood, M. (ed.) Development Update, 5(3):17-43.

OGDEN, J., ESIM, S. \& GROWN, C. 2004. Expanding the care continuum for HIV/AIDS: bringing carers into focus. International Center for Research on Women, June 2004.

PASIOURAS, F., GAGANIS, C., \& C. ZOPOUNIDIS, C. 2006. The impact of bank regulations, supervision, market structure, and bank characteristics on individual bank ratings: a cross-country analysis. Review of Quantitative Finance and Accounting, 27(4):403-438.

PATRICK G.Y., HAMMER, S.M., HIRSCH, M.S., SAAG, M.S., SCHECHTER, M., CARPENTER, C.C.J., FISCHL, M.A., GATELL, J.M., GAZZARD, B.G., JACOBSEN, D.M., KATZENSTEIN, D.A.,

MONTANER, J.S.G., RICHMAN, D.D., SCHOOLEY, R.T., THOMPSON, M.A., VELLA, S. \& VOLBERDING, P.A. 2004. Treatment for adult HIV infection: 2004 recommendations of the International AIDS Society-USA Pane". JAMA, 292:251-265.

PRAHALAD, C.K. 2005. The fortune at the bottom of the pyramid, Wharton School Publishing, Upper Saddle River, NJ.

PRAHALAD, C.K. \& HAMMOND, A. 2002. Serving the world's poor, profitably. Harvard Business Review, 80(9):4-11.

PRAHALAD, C.K. \& HART, S.L. 2002. The fortune at the bottom of the pyramid. Strategy + Business, 26:1-14.

RACANELLI, V.J. 2006. Finding riches on the new frontier. Barrons, 86(45):50-52.

RUSSELL, S. 2003. The economic burden of illness for households. Working paper, University of East Anglia, Norwich, UK.

SEBESTA, D.S. \& LAPLANTE, M.P. HIV/AIDS, Disability and employment, Institute on Disability and Rehabilitation Research (US), US Department of Education, Washington, DC. 
SIKKEMA, K.J., HANSEN, N.B., MEADE, C.S., KOCHMAN, A. \& LEE, R.S. 2005. Improvements in health-related quality of life following a group intervention for coping with AIDS-bereavement among HIVinfected men and women. Quality of Life Research, 14(4):991-1005.

SMITH, A.M. \& REYNOLDS, N.L. 2001. Measuring cross-cultural service quality: a framework for assessment. International Marketing Review, 19(5):450-481.

STEENKAMP, J.B.E.M. 2005. Moving out of the silo: a call to arms for conducting international Marketing research. Journal of Marketing, 69 (Oct):6-8.

TAYLOR, B. 2001. HIV, stigma and health: integration of theoretical concepts and the lived experiences of individuals. Journal of Advanced Nursing, 35(5):792-798.

UNICEF REPORT: THE STATE OF THE WORL'D CHILDREN. 2007. Moccia, P. (ed.) Available at http://www.unicef.org/sowc07/docs/sowc07.pdf (accessed 28 September 2010).

UYS, L. \& CAMERON, S. 2004. Home-based HIV/AIDS care, Oxford University Press: Cape Town, SA. VAN AARDT, C.J. 2002. The femographic impact of HIV/AIDS on provinces and living standards measure (LSM) groups in South Africa, 1996-2011. Bureau of Market Research, University of South Africa, Research Report 310, Pretoria.

VAN AARDT, C.J. 2004. The projected impact on HIV/AIDS in South Africa, 2003-2015. Bureau of Market Research, University of South Africa, Research Report 325, Pretoria.

VAN DYK, A. 2005. HIVAIDS - Care \& counseling. A multidisciplinary approach, ( ${ }^{\text {rd }}$ ed.) Pearson Education South Africa.

VAN WYK, J., DAHMER, W. \& CUSTY, M.C. 2004. Risk management and the business environment in South Africa. Long Range Planning, 37(3):259-276.

VAN WYK, N. \& LEMMER, E. 2007. Redefining home-school-community partnerships in South Africa in the context of the HIV/AIDS pandemic. South African Journal of Education, 27(2):301-316.

WEISER, S., WOLFE, W., BANGSBERG, D., THIOR, I., GILBERT, P., MAKHEMA, J.,

KEBAABETSWE, P., DICKENSON, D., MOMPATI, K., ESSEX, M. \& MARLINK, R. 2003. Barriers to antiretroviral adherence for patients living with HIV infection and AIDS in Botswana," JAIDS Journal of Acquired Immune Deficiency Syndromes, 34(3):281-288.

WOLD, H. 1974. Causal flows with latent variables. European Economic Review, 5:67-86.

ZUNGU, N.G. 2002. Understanding the relevance of young culture in the fight against HIV/AIDS epidemic in South Africa: youth in privately owned flats and university residences in Durban, South Africa.

International Conference on AIDS, University, Durban, South Africa, Jul 7-12:14. 